\title{
Prognostic value of immunological data, in vitro antibody production, and virus culture in vertical infection with HIV-1
}

\author{
Hospital la Paz, \\ Madrid, Spain, \\ Immunology Unit \\ M C García Rodriguez \\ A Ferreira \\ G Fontán

\section{Department of} \\ Obstetrics \\ I Bates

\section{Department of Paediatrics I de José \\ F Hawkins} \\ Service of \\ Microbiology \\ R Martinez-Zapico \\ Correspondence to: \\ Dr M C García Rodriguez, \\ Unidad de Inmunología, \\ Hospital la Paz, Paseo de \\ Hospital la Paz, Paseo de \\ 28046, Spain. \\ Accepted 20 January 1995
}

\author{
M C García Rodriguez, I Bates, I de José, F Hawkins, R Martinez-Zapico, A Ferreira, \\ G Fontán
}

\begin{abstract}
The prognostic value of immunological indices, in vitro antibody production, and virus culture pattern at 3 months of age was estimated in 35 infants infected by HIV-1 from a cohort of 298 babies born to HIV-1 seropositive mothers and followed up from birth. At 1 year old, 15 of these infants were classified as stage $P-1$ (according to the Centers for Disease Control classification) seven were P-2A, and seven had AIDS. Significantly higher CD8 percentages, lower percentages and absolute value of CD4, and lower CD4/CD8 ratios at 3 months were observed in infants with severe symptoms at 1 year of age when compared with those who were asymptomatic at this age. Seventy seven per cent of infants with a 'rapid' virus culture when 3 months old had developed AIDS or had died by 1 year of age and only $8 \%$ of those with 'slow' virus culture had AIDS when 1 year old. Moreover, $100 \%$ of those who were asymptomatic at 1 year had a slow virus culture at 3 months. Significant statistical association was found between the virus replication pattern at 3 months and the clinical stage at 1 year of age.

(Arch Dis Child 1995; 72: 498-501)
\end{abstract}

Keywords: HIV-1 culture, HIV-1 vertical transmission, AIDS.

HIV-1 infection in children is usually due to vertical transmission during pregnancy and/or delivery. The rate of HIV-1 transmission from infected mothers to their offspring varies from $7-45 \%$ with higher rates reported in African studies. ${ }^{1-4}$ In our hospital the rate of vertical transmission is $13 \%$, not much different from the $14.4 \%$ in the European Collaborative Study. ${ }^{5}$ The results of several retrospective studies indicate that HIV-1 infection can take two clinical forms in children. ${ }^{67}$ Some children present with symptoms in the first weeks of life and develop severe immunodeficiency during the first year with early and severe illness. Other children show a late presentation of symptoms followed by a slow clinical course. This double pattern can be explained by several factors: (a) a different time for infection (in utero or perinatal) ${ }^{8}$; (b) the biological properties of the virus with higher or lower viral replication capacity ${ }^{9}$; (c) the cellular tropism for CD4 $\mathrm{T}$ cells and/or monocytes ${ }^{10}$; (d) the mother's clinical stage of infection during pregnancy ${ }^{1112}$; and (e) the possible role of cofactors activating HIV-1 replication. ${ }^{13}$ In adults the rate of decline of CD4 lymphocytes and virological parameters, such as high level persistent replication, ${ }^{14} 15$ may be good predictive markers of clinical outcome. ${ }^{16}$ In children little information is available on the prognostic value of these and other markers on the clinical outcome.

We studied a cohort of infants born to HIV1 infected mothers and followed up from birth. We investigated the prognostic value of immunological data and the in vitro biological properties of the virus in order to identify at 3 months of age those who will develop severe immunodeficiency with serious infections in the first year of life and those in whom the disease will progress slowly and is probably similar to that observed in adults.

\section{Subjects and methods}

STUDY POPULATION

Two hundred and ninety eight infants born to HIV seropositive mothers and attending the paediatric department of $\mathrm{La} \mathrm{Paz} \mathrm{Hospital,}$ Madrid form the basis of this study. All the infants were assessed clinically and immunologically during the first 72 hours of life and every three months thereafter. Only the 268 infants born 12 months or more before the date of analysis are included in this study. Thirty five of them had HIV infection diagnosed based on two of the following criteria: positive HIV-1 antigen test, positive HIV-1 virus culture, or in vitro HIV-1 antibody production on more than two samples. The infected infants were classified according to the Centers for Disease Control classification. ${ }^{17}$ At 1 year of age, 15 infants had infection but no symptoms (P-1) and 20 had infection and were symptomatic $(P-$ 2 ). Seven of the patients classified as $\mathrm{P}-2 \mathrm{had}$ only non-specific clinical manifestations (P-2A subclass) and in 13 P-2 patients these manifestations were associated with the more severe symptoms that are included in the other P-2 subclass (AIDS). Six of these 13 patients with severe symptoms died of HIV related illness at the median age of 5 months. The remaining 233 infants were considered to be uninfected. All these children are enrolled in the European Collaborative Study. 518

In this study we analysed the immunological data and virus culture patterns at 3 months of age to investigate an association between immunological alterations or the biological 
Immunological data at 3 months of age in infants infected with HIV-1; results are mean $(S D)$

\begin{tabular}{|c|c|c|c|c|}
\hline & $P-1^{\star}$ & $P-2 A^{\star}$ & $A I D S^{\star}$ & $\begin{array}{l}p \text { Value } \\
\text { (by } \\
\text { ANOVA) }\end{array}$ \\
\hline 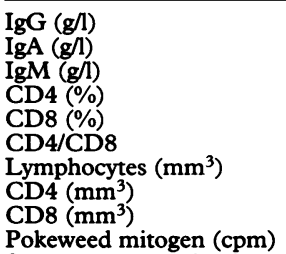 & $\begin{array}{c}7 \cdot 52(4 \cdot 07) \\
0 \cdot 55(0 \cdot 57) \\
0 \cdot 95(0 \cdot 6) \\
37(15) \\
25(9) \\
1 \cdot 80(1 \cdot 24) \\
6699(3129) \\
2455(1544) \\
1811(1234) \\
15793(11545)\end{array}$ & $\begin{array}{c}8 \cdot 54(5 \cdot 11) \\
0 \cdot 69(0 \cdot 65) \\
0.99(0 \cdot 49) \\
34(10) \\
27(13) \\
1 \cdot 64(1 \cdot 13) \\
6612(2568) \\
2083(522) \\
2097(1871) \\
8110(2796)\end{array}$ & $\begin{array}{c}8 \cdot 59(5 \cdot 27) \\
0 \cdot 63(0 \cdot 49) \\
1 \cdot 34(1 \cdot 06) \\
21(8) \\
41(9) \\
0 \cdot 56(0 \cdot 27) \\
4447(2849) \\
1035(792) \\
1971(1562) \\
10079(8109)\end{array}$ & $\begin{array}{l}\text { NS } \\
\text { NS } \\
\text { NS } \\
0 \cdot 006 \\
0 \cdot 0006 \\
0.0053 \\
\text { NS } \\
0.0092 \\
\text { NS } \\
\text { NS }\end{array}$ \\
\hline $\begin{array}{l}\text { Spontaneous production o } \\
\text { IgG } \\
\text { IgA } \\
\text { IgM }\end{array}$ & $\begin{array}{l}\text { immunoglobulins } \\
627(655) \\
364(655) \\
991(2185)\end{array}$ & $\begin{array}{l}(\mu g / 1) \\
1276(943) \\
637(587) \\
228(130)\end{array}$ & $\begin{array}{c}1025(1217) \\
1571(3210) \\
772(804)\end{array}$ & $\begin{array}{l}\text { NS } \\
\text { NS }\end{array}$ \\
\hline
\end{tabular}

${ }^{\star}$ Clinical status at 1 year of age. $\mathrm{NS}=$ not significant, $\mathrm{cpm}=$ counts/minute.

properties of the virus and the disease outcome. At this age 21 of the 35 infected infants were classified as $\mathrm{P}-1$, seven $\mathrm{P}-2 \mathrm{~A}$, and seven had developed AIDS.

\section{METHODS}

Serum immunoglobulins concentrations were measured by laser nephelometry (Array Protein System, Beckman Instruments). Lymphocyte subsets were assessed using monoclonal antibodies conjugated to either fluorescein isothyocyanate or phycoeritrin. Flow cytometric analysis was carried out in a FACScan Cytometer (Becton Dickinson).

Peripheral blood mononuclear cells (PBMC) were isolated from heparinised fresh blood by Ficoll-Hypaque gradient centrifugation. The proliferative response of PBMC was performed by a standard technique ${ }^{19}$ using pokeweed mitogen (Gibco) at $1 \mu \mathrm{g} / \mathrm{ml}$.

\section{In vitro immunoglobulin production}

This was measured by culturing $2.5 \times 10^{5}$ PBMC in a final volume of $250 \mu \mathrm{l}$ of supplemented RPMI culture medium (Flow Laboratories) in the absence of pokeweed mitogen. Culture supernatants were harvested on the seventh day of culture and the immunoglobulins produced were measured by an enzyme linked immunosorbent assay (ELISA). ${ }^{20}$

\section{In vitro HIV-1 antibody production}

PBMC washed twice were cultured at $2.5 \times 10^{6} / \mathrm{ml}^{21}$ in RPMI medium containing $10 \%$ fetal calf serum (Flow Laboratories), $1 \%$ L-glutamine, and penicillin-streptomycin. Subsequently, supernatants were recovered at seven days, diluted $1 / 2$, and tested for the presence of HIV-1 antibody according to the commercial recommendations of the western blot kit (Sanofi Diagnostics Pasteur). As this test has a low specificity in the first two months of age, ${ }^{22}$ only the results obtained after this period were considered for diagnosis.

\section{Virus culture}

In brief, ${ }^{23} 5 \times 10^{6} \mathrm{PBMC}$ from healthy donors previously stimulated by phytohaemagglutinin during 48 hours, were cultured with an equal number of patient cells for one month in RPMI medium with $10 \% \mathrm{~T}$ cell growth factor (Cellular Products), 1\% glutamine, 10\% fetal calf serum, and $1 \mu \mathrm{g} / \mathrm{ml}$ Polybrene (Sigma). Supernatants were removed twice a week and complete medium was replaced. These samples were investigated for the presence of p24 antigen using a commercial enzyme immunoassay (Ag I, Sanofi Diagnostics Pasteur).

\section{Statistical analysis}

Quantitative data are expressed as mean (SD) and qualitative data as a percentage. A one way analysis of variance (ANOVA) was performed to compare quantitative data between $\mathrm{P}-1, \mathrm{P}-$ $2 \mathrm{~A}$, and AIDS groups as a parametric test and the Kruskal-Wallis test as a non-parametric test. We found similar results in both tests therefore results from ANOVA are reported. Pairwise comparisons were studied by Fisher's PLSD test $(\alpha=0.05)$. Association between the virus replication pattern at 3 months of age and the clinical stage at 1 year was studied by the $\chi^{2}$ test. All tests used were two tailed and the threshold of significance was $0 \cdot 05$.

\section{Results}

The table shows immunological data at 3 months of age by clinical status at 1 year for 35 infected infants. Significantly lower CD4 percentages $(p=0.006)$ were observed in infants who subsequently, at 1 year, had severe symptoms (AIDS) compared with those that at this age had mild symptoms or remained asymptomatic $(P-1)$. The percentages of $\mathrm{CD} 8$ were significantly higher $(p=0.006)$ in those who at 1 year had AIDS when compared with those who were classified as P-2A or asymptomatic. We found similar differences $(p=0.005)$ in the CD4/CD8 ratio. At 3 months the CD4 absolute values were significantly lower $(p=0.009)$ in those infants who developed AIDS in the first year compared with those who at 1 year were diagnosed as P-1 or P-2A.

The bands found on western blot of in vitro HIV-1 antibody production by PBMC at 3 months of age were similar in infants classified as $\mathbf{P} 2$ and $\mathbf{P 1}$.

In only 25 infected infants was it possible to perform virus culture. In virus culture, antigen concentrations higher than $30 \mathrm{pg} / \mathrm{ml}$ in three successive supernatants were considered as positive. We found two patterns in relation to p24 antigen values in the supernatants (figure): 'rapid' with high p24 antigen concentrations $(>100 \mathrm{pg} / \mathrm{ml})$ from the first supernatant and 'slow', with constantly low values of p24 antigen during the month of culture. Ten of 13 $(77 \%)$ of the infants with rapid virus culture at 3 months had AIDS or had died before age 1 year, but only $1 / 12(8 \%)$ of those with a slow virus culture pattern had been diagnosed with AIDS when 1 year old. Ten of $11(91 \%)$ of those who at 1 year old had AIDS diagnosed had a rapid culture virus at 3 months of age. Moreover, all infants who were asymptomatic 


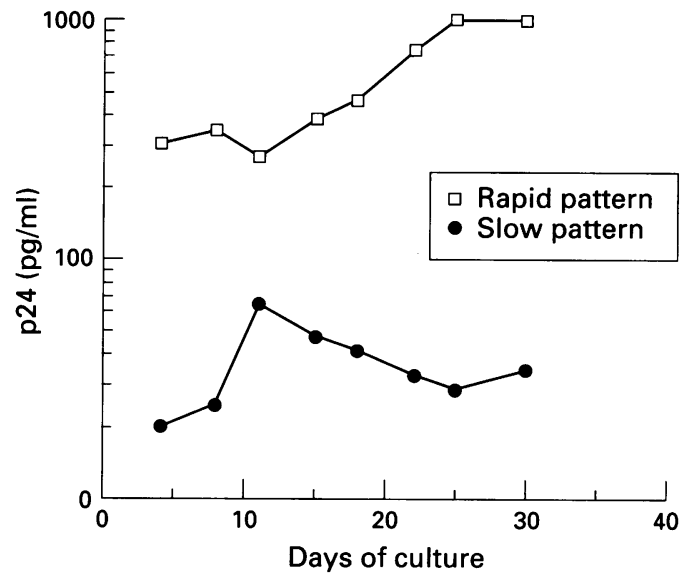

$H I V-1$ replication patterns from two infected children.

at 1 year had a slow virus culture at 3 months of age. The association between virus replication pattern at 3 months of age and the clinical stage at 1 year was statistically significant $(p=0 \cdot 0003)$.

\section{Discussion}

In a previous report we found IgG and IgA hypergammaglobulinaemia, increased spontaneous production of immunoglobulins in vitro, and a decreased percentage of $\mathrm{CD} 4 \mathrm{cir}-$ culating cells in most of our HIV-1 infected patients at the age of 3 months when compared with uninfected infants. ${ }^{24}$ Further follow up of these infants showed that these immunological abnormalities were early, persistent, and generally progressive. Hutto et al found similar results in a prospective study. ${ }^{4}$

In the present study the CD4 and CD8 percentages and the CD4/CD8 ratio at 3 months of age were associated with clinical progression at 1 year. We also observed a significant decrease in the CD4 absolute value at 3 months in infants who during the first year of life had severe symptoms (AIDS) compared with infected asymptomatic infants. However, although these immunological alterations at 3 months are closely linked with the clinical stage, their prognostic value is low. So, when we considered all 35 infected infants at 3 months of age, 11 had a CD4 absolute count below the fifth centile, ${ }^{25}$ but when those with severe symptoms at 3 months were excluded only two infants in the P-2A and two in the P-1 category had a CD4 count below the fifth centile. Our results confirm other reports, ${ }^{18} 26$ that immunological abnormalities at 3 months of age have a low prognostic value and are not useful to predict which asymptomatic infants will develop early and severe symptoms before 1 year.

The results contradict those of an Italian study in children where early immunological abnormalities preceded the onset of symptoms, ${ }^{27}$ suggesting that early alterations have predictive prognostic value rather than diagnostic value. This discrepancy could be explained by the fact that the immunological data in that study referred to measurements between 1 and 6 months of age, while in our present work all examinations were performed when the infants were 3 months old.
In HIV-1 infected adults a low response to pokeweed mitogen before the decrease of CD4 $\mathrm{T}$ cells has been considered to be a predictor for disease progression. ${ }^{27} 28$ It has also been suggested that rapid viral replication in asymptomatic adults may be a prognostic factor ${ }^{16}$ as in cohorts of adults with a widely variable clinical outcome the viruses isolated from asymptomatic patients replicate slowly, while viruses from symptomatic ones replicate rapidly. ${ }^{29}$ Similar results have been recorded in children. Those who already had symptomatic HIV-1 infection showed a rapid viral growth pattern in vitro and those asymptomatic had mostly a slow replication. ${ }^{9}{ }^{23}$ In a recent paper, de Rossi et al reported 18 infants from 4 to 8 weeks of age who were identified as infected with HIV-1. At this time, those infected children who had rapid and high virus replication, progressed faster to AIDS than those with a slow replication pattern. ${ }^{10}$ In their cohort no patient with a slow replication pattern at this early age had AIDS at 1 year, but $5 / 7(71 \%)$ of those with rapid replication had developed AIDS by the time they were 1 year old.

Our results confirm and extend these findings and we found a significant association between the virus replication pattern at 3 months of age and the presence or absence of symptoms during the first year of life. Seventy seven per cent of the infants with a rapid replication pattern at 3 months old developed symptomatic HIV-1 infection during the first year of life and $100 \%$ of those who were asymptomatic ( $\mathrm{P}-1)$ by 1 year old had a slow virus culture at 3 months. When we exclude those infants who already had severe symptoms at 3 months in order to know the true predictive value of the culture pattern, this association persists. Therefore we think that the virus culture pattern at 3 months is associated with the clinical stage. Moreover, this viral characteristic has prognostic value for identifying the $30 \%$ of infected infants who will develop severe immunodeficiency (AIDS) in the first year of life. ${ }^{18}$ In agreement with these results Rogers et al found in a retrospective study a strong association between the early and severe course of HIV-1 infection and the viral DNA burden at birth. ${ }^{30}$ Burgard et al found a less strong association with virus culture at birth. However, birth is not the best moment to establish prognosis, as only $30-50 \%$ of infected children can be diagnosed by the polymerase chain reaction or virus culture at this time. ${ }^{13} 32$

We considered that 3 months of age is the appropriate time for a prognostic evaluation. At this age, virus culture and in vitro HIV-1 antibody production showed, in our laboratory, a sensitivity and specificity near to $100 \%$. Currently we are also using the polymerase chain reaction for early diagnosis of HIV-1 vertical transmission and have found a similar sensitivity and specificity at this age. These techniques are less reliable when used before 2 months of age. The assay for vitro HIV-1 antibody production could give false positive results during the first 2 months by possible persistence of maternal cells in the 
infant's blood. ${ }^{22}$ Both virus culture and the polymerase chain reaction could give false negative results at this age because it is possible that infants infected just before or during delivery have not yet a sufficient viral burden. ${ }^{33} 34$

In conclusion, the significant association found between the viral replication pattern at 3 months and clinical stage at 1 year increases understanding about the prognosis of vertically acquired HIV infection and could be of help in future therapeutic trials.

We thank P Acebes, M Arribas, J Borrega, I Fernandez, and C Sanchez Caro for technical work.

1 Mok JYQ, Hague RA, Yap PL, et al. Vertical transmission of HIV: a prospective study. Arch Dis Child 1989; 64: 1140-5.

2 Ryder RW, Nsa W, Hassig SE, et al. Perinatal transmission of the human immunodeficiency virus type 1 to infants of seropositive women in Zaire. N Engl fु Med 1989; 320 1637-42.

3 Blanche S, Rouzioux C, Guihart Moscato ML, et al. A prospective study of infants born to women seropositive for human immunodeficiency virus type 1 . N Engl $f$ Med 1989; 320: 1643-8.

4 Hutto C, Parks WP, Lai S, et al. A hospital-based prospective study of perinatal infection with human immunodefitive study of perinatal infection with human imm
ciency virus type 1 . $₹$ Pediatr $1991 ; 118: 347-53$.

5 European Collaborative Study. Risk factors for mother-tochild transmission of HIV. Lancet 1992; 339: 1007-12

6 Blanche S, Tardieu M, Duliege AM, et al. Longitudinal study of 94 symptomatic infants with perinatally acquired human immunodeficiency virus infection. $A m \mathcal{F}$ Dis Child 1990; 144: 1210-5.

7 Scott GB, Hutto C, Makuch RW, et al. Survival in children with perinatally acquired human immunodeficiency virus type 1 infection. N Engl F Med 1989; 321: 1791-6.

8 McCune JM. HIV-1: the infective process in vivo. Cell 1991 64: $351-63$.

9 Alimenti A, Luzuriaga K, Stechenberg B, Sullivan JL. Quantitation of human immunodeficiency virus in vertically infected infants and children. $\mathcal{F}$ Pediatr 1991; 119: 225-9.

10 De Rossi A, Giaquinto C, Ometto L, et al. Replication and tropism of human immunodeficiency virus type 1 as predictors of disease outcome in infants with vertically predictors of disease outcome in infants with
acquired infection. $\mathcal{F}$ Pediatr 1993; 123: 929-36.

11 St Louis ME, Kammenga M, Brown CH, et al. Risk for perinatal HIV-1 transmission according to maternal 1993; 269: 2853-9.

12 Blanche S, Mayaux MJ, Rouzioux $\mathrm{CH}$, et al. Relation of the course of HIV infection in children to the severity of the disease in their mothers at delivery. $N$ Engl $\mathcal{F}$ Med 1994 330: 308-12.

13 Delfraissy JF, Blanche S, Rouzioux C, Mayaux MJ. Perinatal HIV transmission. Facts and controversies. Immunol Rev 1992; 3: 305-27.

14 Fahey JL, Taylor JMG, Detels R, et al. The prognostic value of cellular and serological markers in infection with human immunodeficiency virus type 1 . N Engl $f \mathrm{Med}$ 1990; 321: 1141-8.

15 Phillips AN, Lee CHA, Elford J, et al. p24 antigenemia, CD4 lymphocyte counts and the development of AIDS. AIDS 1991; 5: 1217-22.

16 Schnittman SM, Greenhouse JJ, Psallidopoulos MC, et al Increasing viral burden in CD4 $\mathrm{T}$ cells from patients with human immunodeficiency virus (HIV) infection reflects rapidly progressive immunosuppression and clinical rapidly progressive immunosuppression

17 Centers for Disease Control. Classification system for HIV1 infection in children under 13 years of age. $M M W R$ 1987; 15: 225-36

18 European Collaborative Study. Children born to women with HIV-1 infection: natural history and risk of transmission. Lancet 1991; 337: 253-60.

19 Janossy G, de la Concha E, Wasdall M, Plats-Mills TAE The effect of purified mitogenic proteins from pokeweed on human $\mathrm{T}$ and $\mathrm{B}$ lymphocytes in vitro. Clin Exp Immunol 1976; 26: 108-17.

20 Fontán G, de la Concha E, García Rodriguez MC, et al. Severe combined immunodeficiency with disbalance and functional abnormalities in the T lymphocyte subsets. Clin Immunol Immunopathol 1982; 24: 432-9.

21 Amadori A, De Rossi A, Giaquinto C, et al. In vitro production of HIV specific antibody in children at risk of AIDS. tion of HIV specific antib

22 Amadori A, De Rossi A, Chieco Bianchi L, et al. Diagnosis of human immunodeficiency virus 1 infection in infants: in vitro production of virus specific antibody in lymphocytes. Pediatr Infect Dis f 1990; 9: 26-30.

23 De Rossi A, Pasti M, Mammano F, et al. Perinatal infection by human immunodeficiency virus type 1 (HIV-1): relationship between proviral copy number in vivo, viral properties in vitro and clinical outcome. $\mathcal{F}$ Med Virol 1991; 35: 283-9.

24 García Rodriguez MC, Omeñaca F, Ferreira A, et al. Immunological follow-up in children born to HIV-1 infected mothers. Acta Paediatr Scand 1991; 80: 1183-91.

25 European Collaborative Study. Age-related standards for T-lymphocyte subsets based on uninfected children born to HIV-1 infected women. Pediatr Infect Dis $\mathcal{f} 1992$; 11: to HIV-1

26 European Collaborative Study. CD4 T cell count as predictor of Pneumocystis carinii pneumonia in children born to mothers infected with HIV. $B M F$ 1994; 308: 437-40.

27 De Martino M, Tovo PA, Galli L, et al. Prognostic significance of immunologic changes in 675 infants perinatally exposed to human immunodeficiency virus. $f$ Pediatr 1991; 119: 702-9.

28 Hofmann B, Osskov Lindhardt B, Gerstoft J, et al. Lymphocyte transformation response to pokeweed mitogen as a marker for the development of AIDS and AIDS related symptoms in homosexual men with HIV antibodies. $B M \mathcal{F}$ 1987; 295: 293-6.

29 Mathez D, Paul D, de Belilovsky C, et al. Productive human immunodeficiency virus infection levels correlate with AIDS related manifestations in the patient. Proc Natl Acad Sci USA 1990; 87: 7438-42.

30 Rogers MF, Ou CY, Rayfield M, et al. Use of the polymerase chain reaction for early detection of the proviral merase chain reaction for early detection of the proviral born in seropositive mothers. $N$ Engl f Med 1989; 320: born in sero. $1649-54$.

31 Burgard M, Mayaux MJ, Blanche $S$, et al. Viral culture and antigenemia for the diagnosis of human immunodeficiency virus infection in neonates. $N$ Engl $\mathcal{f}$ Med 1992 327: 1192-7.

32 Borkowsky W, Krasinski K, Pollack H, Hoover W, Kaul A Ilmet-Moore T. Early diagnosis of human immunodeficiency virus infection in children $<6$ months of age: comparison of polymerase chain reaction, culture and plasma antigen capture techniques. F Infect Dis 1992; 166: 616-9.

33 De Rossi A, Ades AE, Mammano F, et al. Antigen detection, virus culture, polymerase chain reaction, and in vitro antibody production in the diagnosis of vertically transantibody production in the diagnosis of verticall
mitted HIV-1 infection. AIDS 1991; 5: 15-20.

34 Krivine A, Firtion G, Cao L, Francoual CH, Henrion R, Lebon P. HIV replication during the first weeks of life. Lancet 1992; 339: 1187-9. 